\title{
Reading of Qing Ming and its derivative forms-From the Perspective of Cognitive Poetics
}

\author{
Linling Yang \\ Guangdong University of Science and Technology, 523083
}

\begin{abstract}
Chinese poetry plays an important part in Chinese literature, and has been the focus of research and the way for Chinese people savor life and for their self-cultivation. The appearance of cognitive poetics shed the new light on the research of literature, especially on poetry. It rose up from the 1970s, combining the theories of literature and those of linguistics, and emphasized the recording and interpreting the psychological state of readers or, simply their reading of the texts which involves information processing, individual psychological states, it was naturally connected with the researches on the mind, cognition, and of course the investigation of language itself. This paper mainly attempts to applying cognitive linguistic theories to interpreting a very renowned Chinese ancient poem Qing Ming, written by Du.mu, a poet from Tang dynasty, and meanwhile digs it deeper about the above phenomena: various combinations of the same elements should have such different artistic and aesthetic effect.
\end{abstract}

Keywords: Qingming; poetics; unscramble

\section{Pure Brightness Day (Qingming Festival) \\ By Dumu}

Around the Pure Brightness Day it drizzles quite often,

Men on the way to mourning the dead seem heart-broken.

"Where," may I ask, "to find an inn to drown my grievance"?

The herd boy points to Apricot Hamlet in the distance.

It rains in Qingming Festival, wandering people come and leave, being extremely sad.

Helplessly I resort to wine, a shepherd boy, points tavern named Apricot Hamlet.

[Qingming Shijie]Yu[Fenfen], Lushang, Xingren, [Yuduanhun].

Jiewen: "Jiujiahechu?", [You Mutong] Yaozhi---"Xinghuacun"

Extracted from If only we were always in the moment I first saw you By An Yiru (Note: The latter two lines are the genres changed from the first poem with only difference in punctuation in Chinese)

\section{Information about the lines}

The three above different forms of the Qing Ming, are poem, song lyrics, Yuanqu respectively from up to bottom. It mainly describes the scene of Chinese traditional Qing Ming festival in the writer's mind eye. Since tradition has it that on that day, in memory of the deceased relatives and ancestors, All Chinese people will go to the graveyard to sweep their tombs, so it is also called tomb-sweeping festival. Between those lines, it is easy to get that: It was a rainy day that day, adding more sorrow and misery to the sadness of the people whose beloved ones has pass away. One the way to the resting place of the dead, people are deeply indulged in sorrow and low spirit, as if their soul were separated from their bodies and hunted around. Seeing and being affected by the scene in front, the writer, being alone and wandering all the year round, thinking of his passed away grandfather and his own fate, was more overwhelmed with nameless misery. He wants to get rid of this feeling and to be indifferent, so he thoughts of drinking, as usual. After asking a cattle boy, he headed for the apricot village, the name of one tavern nearby, which the cattle boy pointed to. This is the rough ideas of this poem for the general understanding of it, and the detailed analyzing on the basis of cognitive linguistics will be presented step by step next. actually in Chinese, the above three have the same character with only the difference on the punctuation, which should yield three different genres. And now we first get down to the original form of this lines: poem, and then delved into this mysteriously genre transition.

This is an open-access article distributed under the terms of the Creative Commons Attribution Non-Commercial License

(http://creativecommons.org/licenses/by-nc/4.0/), which permits unrestricted non-commercial use, distribution, and reproduction in any medium, provided the original work is properly cited. 


\section{Iconicity of Chinese character and schematic explanation of Qing Ming}

The Iconicity introduced by Charles Sanders Peirce mainly denotes the corresponding relationship between linguistic forms and the events, which is on the opposite side to the arbitrariness between signifier and signified. It maintains that language is the representation of the thought and the recording note of human experience, thus sharing some similarities, either in sound, shapes, complexity, or the sequence of the event and like that. The one of most convincing evidence is the Chinese ancient inscriptions on the tortoise shell, which is called as "Jiaguwen" in Chinese, since its shape is almost the imitation of the real THING outside. Therefore, Chinese characters combine the form and meaning through images. This iconicity of language allows poem to convey the endless meaning with four lines. According to different criteria, iconicity displays in different ways, such quantitative iconicity, distance iconicity, sequential iconicity and image iconicity and so on. In recent years, the studies on iconicity and images touches on the Chinese ancient poems, taking the unique ideogram feature of Chinese characters and discrete syntactic structure into consideration. Ancient Chinese poem pays much more attention to the indescribable image than the limited number of forms, which claims the validity of iconicity. In ancient Chinese poems, the image is the result of poet's initiative or subjective projection of outside world to his mental space and then condenses it into the physical forms: characters, which is although bound in length, but endless in MEANING with not deviating from the resonating theme. Here iconicity bridges the gap between the different interpretations and the sympathy and empathy. Because according to its definition, iconicity to a large extent reflects that: people make responses according to the real objective world, namely, describing and explaining the outside world, at interval of involving subjective feeling, and then change it to be better. Therefore, language, created to meet the demand for communication, is the similar abstraction of the world reality. For example, look at the following sentence: He gets up in the morning and then has the breakfast downstairs. But we can not say: He has the breakfast downstairs and then gets up in the morning. In linguistic level, it should be grammatical without violating syntactical rules. As for this point, we should rely on our background world knowledge: accumulated experience. As the usual daily practice, we at first get up and then do some washing to eat breakfast. So the second sentence is not in comply with the reality. That is to say, our language structure mostly imitates the sequence of time of the event that happens, which is termed as sequential iconicity, to name just this one example for illustration. In this poem, the most important image is the RAIN created by the rain in nature, being combined with poet's subjunctive feeling. In traditional Chinese literature works, rain is associated with many images, such as rain of delight, rain of misery, and rain of Enlightenment and like that. The rain in Qing Ming will always embodies much more than sadness, Between the lines in this poem, poet borrows the nature rain and adds his own personal feelings and the atmosphere in the special festival day to create a new image, arousing empathetic feelings and pours out his distress, disappointment and helplessness. The lines is just the bound physical conveyance of this feelings. This is the iconicity of the image. In addition, as it is suggested earlier, Chinese is a kind of ideograph, so many Chinese characters are shaped like the real object or THING outside the world they denote. In this poem, poet artistically use the such words as "Fenfen" and "Duanhun", as if the soul or ghost haunts there and tinges the scene with another endless agony.

In this poem, what lies behind the fact that the assumedly simple description with four lines about what the poet experienced on that tomb-sweep festival day will provoke so everlasting sympathetic feelings and resonance in the generations to come is actually the schematic system of concept. Qing Ming itself is a sad concept, on that day, people always target the old days together with the deceased beloved ones, and one thing lead another, all the other sad things are activated, making the festival more wistful. Rain also plays a role to add the depression and it always go hand in hand with sullen, damp, inconvenience and confinement, which arose the negative sides of human affective world. The last but most important element, wine, is also the essence of this poem from this perspective. In ancient times, the wine, spirit, is always connected with unsuccessful scholars, being indignant, helpless in such chaotic and turbulent society. Drinking, to them, is the only way to be indifferent and get rid of the outside world but always failed in this way, after the total indulgence in drinking, what left was just endless darkness and cruel reality. Misery never goes away from them. Even nowadays, heavily drinking to get rid of the earthy care for the moment is not unusual. The accumulated common experience and sympathetic nature of human being, together with the certain elements in certain circumstances and the poet's eventful life road, rolled into this poem with four lines, making the theme more meaningful and emotion stronger. To sum up, poet continuously constructs context with limited words and integrates the subject emotion with the surrounding scenes, making the poem beautifully meaningful. At the meantime, readers will understand the poem with the combination of initiative and contextual restriction. This perfectly proves the interaction between language and cognition.

\section{Categorization, prototype and decategorization: derivative forms of Qing Ming}

In this part, the last earlier mentioned topic will be delve into. That is, why this poem in its original form can be changed into another forms without adding or deducing the elements in it and the meaning remains unchanged. The exploration of this question will be carried out step by step from the discussion of the hot topics these years in cognitive linguistics: categorization and decategorization. The process for human to know the world is the process of classifying the world, namely, the categorization, which is the most primitive and simple way to understand the world. The earlier scholars thought of the boundaries of all kinds of categories clear-cut with no confusion and intrusion. The most typical idea is the dichotomy, if not this, then that, without any third possibilities. Later, this view for classification failed to explain many phenomena, such as the fuzziness of many concept. Subsequently, cognitive phycologists found that the categories do not have boundary, and they have a range from the prototype member to the most peripheral members within it. Process of categorization, is also the process of identifying the prototype and peripheral members. When taking the categorization and prototype into the literature world, we are actually talking about genre or literature style. According to the different way of conveyance and description and the contents, in literature world, there are many different genres, such as poem, lyrics, novel and Yuanqu, and legend or Hua ben, taking Chinese literature as an example. Here we are just limit to the poem, lyrics and Yuanqu, which is relevant to the topic under discussion. For each type, there must 
be a prototypical member, like what kind of form can be called poem, lyric or Yuanqu. How do we categorize them apart? Here the history of them should be mentioned. Poem, is said to derive from the songs of ancient people, but then developed and broke away from the songs and was established as a kind of literature form on its own right. It had its own characteristics: equal length of each line with every two lines rhymed for rhymed poem, and the whole poem is usually not very long, for example there are four-line, eight-line. The lines with these characteristics are prototype of poem, others being peripheral members, such as ancient poem. Song lyrics, was also derived from ancient music, and it combined the feature of poem and melodies of music to yield the its own form, but it was more closely related to the music than poem, and the ci pai is the names of tone of the various music. The lines under each ci pai has its own features: with the certain length, certain verse. The lyrics are usually composed of two parts: we call former parts and latter part. Yuanqu, also composed with music, derived and developed from lyrics, can be divided into Sanqu, Zaju, Xiaoling, with Xiao ling sharing most similarities with lyrics. It also had various Qupai, the verses. And its length is most flexible among these three. In this case, Qing Ming, in its original form, is poem. But, just as it was suggested before, the boundaries among categories are not clear-cut. Date back to the appearance of Chinese literature, we can easily know that poem is the earliest textual form of literature, and it reached its peak in Tang Dynasty, After Tang Dynasty, all kinds of literature forms develop quickly. It is not difficult to detect all the genres form a chain which entails the transition among different genres. And linguistically speaking, the phenomenon in which the features one peripheral members share with the prototypical member within one category disappear and instead they enjoy the features of nearest category or the categories themselves takes the function of other category by subjective intention is technically called decategorization, actually, a process of exerting subjective initiative. The decategorization can well account for the fact that the same poem can be derived into many other forms. Because poem, lyrics and yuan qu share lot of similarities, which provides the opportunity for the derivation. The second form of this poem is changed into a lyric with slight change on the structure, using a comma to part one line, with the later part being connected with the former part of the next line of being alone, making the structure more flexible and still makes sense. The third form becomes the Yuanqu, by taking some element as Qupai, to sing in thin verse. Therefore, thanks to the fuzzy boundary among categories, decategorization, human subjective initiative, the shift ability among some different literature styles is ensured.

\section{Conclusion}

This paper mainly employs the cognitive linguistic theories to read literature works, especially interpreting Chinese classics. Since Chinese is an ideograph rather than being formal, which conforms to the view of cognitive linguistics that the meaning is most essential in language not the syntax, the logic form of it. The interpretation of language is largely based on human accumulated experience, encyclopedic knowledge. Therefore, application of the theories in Chinese linguistic or literature domain is feasible. Indeed, as this new branch emerges, many Chinese literature works, especially poems, are analyzed with the cognitive linguistic theories, shedding the new light on both Chinese language investigation and literature reading. In any case, understanding the nature of language precedes the reading a literature, after all, language is the most basic element in world filled with different thoughts. As the reading a literature is gradually concerned with the reader's state of mind when processing the information of the text, technically we named this as receptive aesthetics, the combination of cognitive linguistics and literature will be more and more close. The cognitive poetics, hopefully, has a bright and fruitful future. Last point, this paper should not be regarded as an essay, there is no concrete quotations, and also is a little bit short for being an essay. But the author just wants to express and share her ideas out, being enlightened by some insightful opinions from some passages or some books, with a little understanding of the relative theories and notions. Though the paper is pretty rough and fragmental, the precious remark and suggestions from scholars are sincerely looked forward and desired.

\section{References}

1. Peter Stockwell. Cognitive poetics: An introduction [M] London and New York 2002.

2. Vyvyan. Evans and Melanie. Green Cognitive Linguistics: An Introduction [M] Mahwah, New Jersey: Lawrence Erlbaum Associates 2006. 